\title{
Gasification of sugarcane bagasse in supercritical water media for combined hydrogen and power production: a novel approach
}

\author{
F. Safari ${ }^{1} \cdot$ A. Tavasoli $^{1,2} \cdot$ A. Ataei $^{1}$
}

Received: 28 September 2015/Revised: 23 May 2016/Accepted: 27 June 2016/Published online: 12 July 2016

(C) Islamic Azad University (IAU) 2016

\begin{abstract}
A novel process based on supercritical water gasification has been used in this study for co-production of hydrogen and power from sugarcane bagasse as one of the main agricultural wastes of Iran. The cycle of the process was designed first, and then, the thermodynamic equilibrium model of the gasification process was simulated using ASPEN PLUS. The effects of temperature and feed concentration on molar fraction of main components of produced gas were investigated. The temperature was directly correlated with hydrogen production in which hydrogen and carbon monoxide production was favored at higher temperatures. The maximum hydrogen production occurred in the sugarcane bagasse concentrations about 20-30 wt \%. Palladium membrane as a metallic dense membrane was used for separation of highpurity hydrogen. Hydrogen production of $8.55 \mathrm{~kg} / \mathrm{h}$ and electrical power generation of $56 \mathrm{~kW}$ were obtained for the $20 \mathrm{wt} \%$ mixture of bagasse with a mass flow rate of $1000 \mathrm{~kg} /$ $\mathrm{h}$, reactor pressure of 300 bars and temperature of $700{ }^{\circ} \mathrm{C}$.
\end{abstract}

Keywords Cogeneration - Gasification · Hydrogen . Sugarcane bagasse $\cdot$ Supercritical water media

\section{Introduction}

Sustainability in the generation, conservation, and consumption of energy has become very necessary for reaching sustainable development in the context of energy. Research

A. Ataei

abtinataei@gmail.com

1 Department of Energy Engineering, Science and Research Branch, Islamic Azad University, Tehran, Iran

2 School of Chemistry, College of Science, University of Tehran, Tehran, Iran and Development for efficient and environmentally friendly methods of power generation from energy resources would be a great leap forward for sustainable future (Dincer 2012; Safari et al. 2015). Conventional fuels such as crude oil and natural gas are being depleted fast, and the ecological balance has been affected by their combustion products (Shoja et al. 2013; Norouzi et al. 2016). Hence, the renewable and available energy resources could be a sufficient alternative for conventional energy carriers (Midilli et al. 2006; Susanti et al. 2012). Biomass as a carbon neutral resource is one of the most abundant and available energy resources among other known renewable energy resources (Anwar et al. 2014). Agricultural and forestry residues as lignocellulosic biomasses can be used for the production of biofuels or chemicals via novel processing technologies (Yoon et al. 2011; Cohce et al. 2011). Sugarcane bagasse is one of the most abundant lignocellulosic feedstock in Iran. Million tons of it is wasted or burned annually in the lack of conversion industries (Sheikhdavoodi et al. 2014). It can be fermented via biological conversion for ethanol production or gasified via thermochemical conversion for syngas production (Tavasoli et al. 2009). Syngas mostly contains $\mathrm{H}_{2}$, $\mathrm{CO}, \mathrm{CO}_{2}$ and $\mathrm{CH}_{4}$, and it is a valuable gas with wide applications in modern industries (Parthasarathy and Narayanan 2014; Ni et al. 2006). Syngas can be directly used for power generation or purified to obtain high-purity hydrogen or may be converted into long-chain hydrocarbons using Fischer-tropsch synthesis (Nanda et al. 2013).

Power generation via conventional gasification of biomass has been investigated by many researchers (Cohce et al. 2010; Casella and Colonna 2012). In the recent years, supercritical water (SCW) gasification, as a promising method for gasification has been focused by many scientists. SCW gasification is a gasification process which occurs in SCW media (Water in $T>374$ C, 
$P>22.1 \mathrm{Mpa})$. SCW gasification is an efficient technology for conversion of dry or wet agricultural wastes into hydrogen-rich gas with high efficiency (Furusawa et al. 2007; Desnoo and Huang 2013). SCW gasification process does not require drying and takes place at much shorter residence times; a few minutes at most (Basu and Mettanant 2009; Matsumura and Ishibe 2009). Water in its supercritical condition has high dispersion and effective heat transfer. It has twofold roles as a reactant and a medium. In this condition, organic compounds can be easily hydrolyzed and decomposed into their monomers (Kruse and Dinjus 2007; Azadi et al. 2009). Therefore, in a novel method, lignocellulosic biomass can be converted into hydrogen-rich gas, and then, electricity and hydrogen can be made simultaneously. Some research in this area has been done by researchers. Whitag et al. presented a system model for the process of gasification of biomass model compounds in SCW media and predicted the influence of some parameters on the molar fraction of gaseous components and thermal efficiency (Whitag et al. 2012). Fiori et al. proposed a conceptual process design for a hydrogen production plant based on SCW gasification. They also investigated the influence of some parameters including biomass concentration and reaction pressure. Results indicated that the minimum concentration of $15-25 \%$ was appropriate for the plant from the viewpoint of energetic analysis (Castello and Fiori 2011, 2015).

However, the process of SCW gasification of bagasse has not been simulated for co-production of hydrogen and power before. This process would be one of the most advanced technologies for renewable energy utilization and industrialization. SCW gasification is being developed mostly in laboratories in bench scale experiments, whereas this research presents a real plant for applying produced syngas from biomass in an actual scale for hydrogen and power production. In this article, sugarcane bagasse as a renewable resource has been deployed for co-production of hydrogen and electricity in a novel system based on SCW gasification. The aim of this research is to develop a novel approach to combined power and hydrogen production through gasification of sugarcane bagasse in SCW media as an environmentally friendly process. The effect of operating parameters in the reactor on the hydrogen production and simulation of a system for simultaneous hydrogen and electricity production is studied. Furthermore, the amounts of power and hydrogen production, as well as efficiencies of the process, are calculated with respect to the determined operating parameters. The main novel investigations of the current study are mentioned below:

- Utilization of sugarcane bagasse as one of the major agricultural wastes of Iran in an environmentally friendly process.
- Production of power in addition to hydrogen in a cycle for the first time using a novel process based on SCW technology.

- Evaluation and validation of the results, according to the some previous experimental results.

- Evaluation of the effect of the operating conditions on the main gaseous products along with energy analysis of the cycle.

This research is conducted in 2015 , by the graduate school of the environment and energy, science and research branch of Islamic Azad University, Tehran, Islamic republic of Iran.

\section{System description}

As mentioned, the objective of this study is to simulate a process for the production of hydrogen and electricity based on SCW gasification of sugarcane bagasse. As shown in Fig. 1, sugarcane bagasse and water are mixed by a mixer and reached supercritical pressure using a highpressure, multistage centrifuge pump. Then, the mixture is preheated in heat exchanger 1 and 2. Heat exchanger 1 is supplied by external heat source, while heat exchanger 2 is supplied by some products of gasification in the cycle. This Heat exchanger can be determined as a regenerator. After that, fluid is ready for reaction in the reactor. This performance of the reactor is analyzed via minimization of Gibbs free energy. This method is used when reaction and heat transfer happen at the same time. This is a constant pressure, isothermal, and exothermic process. After this, products of reactor enter the heat exchanger 1 and reject their heat to the mixture. For this heat exchanger, we consider the $100 \%$ quality for steam to avoid any damage of instruments. In this section, syngas enters the separation unit for extracting its water. Then, hydrogen is separated from other products using palladium membrane (Hysep ${ }^{T M} 60$ ). Generally, there are two categories of membranes which are categorized by their structure; porous membranes and dense membranes. The membrane used in this study is a metallic dense membrane. These kinds are mostly used when high-purity of hydrogen is needed (Kluiters 2004).

This membrane works at near $300{ }^{\circ} \mathrm{C}$ and 60 bars. The separated hydrogen is stored in the same condition. Heat exchanger 2 and air heat exchanger supply the heat that is required for hydrogen separation. For reaching membrane's pressure, an expansion turbine is used which also generates power at the same time. Because of high pressure at this stage, we should expand the gas for the second time to power generation and drop the pressure to $1 \mathrm{~atm}$. After that, syngas enters the torch and is burned to supply the hot 


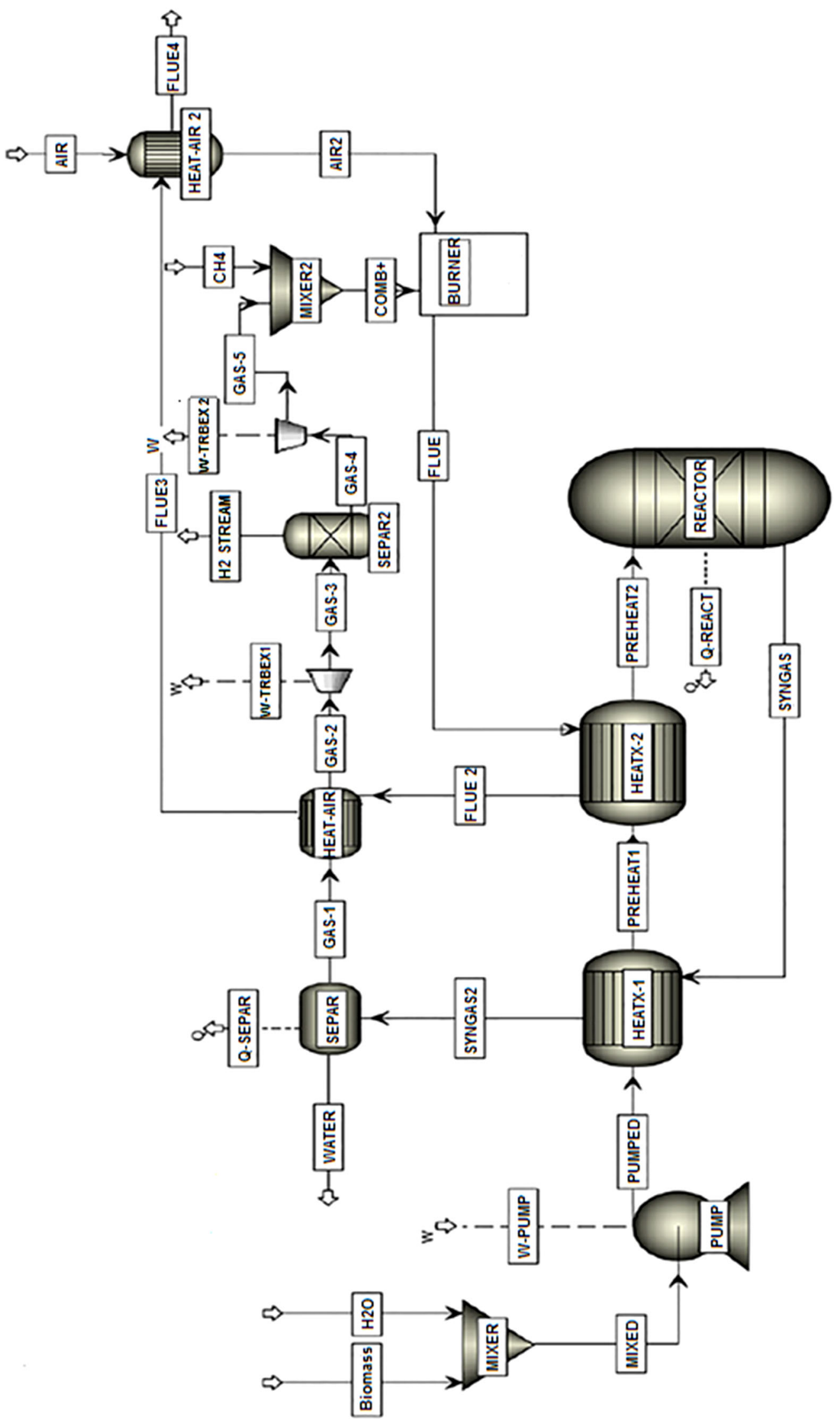

Fig. 1 ASPEN PLUS flow diagram of a process for co-production of hydrogen and power via supercritical water gasification of bagasse 
air needed for the cycle. In this study, gasification process in the reactor has been modeled first, and the effects of reactor's temperature and water loading have been investigated. Then, hydrogen and electricity cogeneration was simulated by ASPEN PLUS program.

\section{Modeling}

\section{Gasification process}

In this study, thermodynamic model is used to analysis of the products of bagasse gasification and study the effect of different parameters such as pressure, reactor's temperature, and water loading into the system. Despite the calculations of thermodynamic model, this method is independent of the design of the gasifier but helps to predict the maximum useful gaseous product. Equilibrium modeling has two primary methods: stoichiometric and non-stoichiometric. Stoichiometric method needs a reference reaction to support all other reactions which modeling is based on that. Gasification reaction is considered as reference reaction in this study. Chemical composition of biomass can be expressed as $\mathrm{CH}_{X} \mathrm{O}_{y} \mathrm{~N}_{Z}$ where $x, y, z$ are the mole ratios of hydrogen to carbon, oxygen to carbon and nitrogen to carbon, respectively. These ratios can be obtained for different biomasses with elemental analysis (CHNSO analysis), which gives the mass fraction of each element in feedstock and the molecular weight of each element, as mentioned in Eqs. (1-3).

$x=\frac{\text { mass fraction }(H) \times \text { molecular weight }(C)}{\text { mass fraction }(C) \times \text { molecular weight }(H)}$

$y=\frac{\text { mass fraction }(O) \times \text { molecular weight }(C)}{\text { mass fraction }(C) \times \text { molecular weight }(O)}$

$z=\frac{\text { mass fraction }(N) \times \text { molecular weight }(C)}{\text { mass fraction }(C) \times \text { molecular weight }(N)}$

The chemical composition of elemental analysis of the sugarcane bagasse which has been used in this study is shown in Table 1. Also, its molecular formula can be written as $\mathrm{CH}_{1.33} \mathrm{O}_{0.44} \mathrm{~N}_{0.01}$.

Table 1 CHNSO analysis of sugarcane bagasse

\begin{tabular}{lc}
\hline Elements & Elemental composition (wt \%) \\
\hline $\mathrm{C}$ & 57.8 \\
$\mathrm{H}$ & 6.44 \\
$\mathrm{O}$ & 34.52 \\
$\mathrm{~N}$ & 0.67 \\
$\mathrm{~S}$ & 0.19 \\
\hline
\end{tabular}

The main governing equation for biomass gasification in SCW media is written as Eq. (4) below:

$$
\begin{aligned}
\mathrm{CH}_{x} \mathrm{O}_{y}+m_{\mathrm{w}} \mathrm{H}_{2} \mathrm{O} \rightarrow & a \mathrm{CO}_{2}+b \mathrm{H}_{2}+d \mathrm{CO}+e \mathrm{H}_{2} \mathrm{O} \\
& +f \mathrm{CH}_{4}
\end{aligned}
$$

where $m_{\mathrm{w}}$ is the amount of water supplied to the system for reaction in supercritical media and $a, b, d, e$, and $f$ are the numbers of moles for $\mathrm{CO}_{2}, \mathrm{H}_{2}, \mathrm{CO}, \mathrm{H}_{2} \mathrm{O}, \mathrm{CH}_{4}$, respectively.

\section{Mass balance}

Mass balance equations are written to find out how many moles we have for each product. Mass balance for carbon, hydrogen, and oxygen are mentioned in Eqs. (5-7), respectively as follows:

$a+d+f=1$

$x+2 m_{\mathrm{w}}=2 b+2 e+4 f$

$y+m_{\mathrm{w}}=a+2 d+e$

\section{Thermodynamic equilibrium}

A thermodynamic equilibrium model is based on equilibrium constant. Equilibrium equations are used to obtain two remaining equations. For an ideal gas in its equilibrium state, the equilibrium constant can be written in the terms of free Gibbs function, which is mentioned as Eq. (8) below:

$K=\exp \left(\frac{-\Delta G}{R T}\right)$

where $R$ is the universal gas constant and equals to $8.314 \mathrm{~kJ} / \mathrm{kmol}$ and $T$ is reaction's temperature and $-\Delta G$ stands for Gibbs free energy of reaction which can be obtained with ideal gas assumption in the form of Eq. (9) as follows:

$-\Delta G=\sum_{i=1}^{n} v_{i} g_{i}(T)$

where $v_{i}$ is stoichiometric coefficient of part $i$ in reaction and $G_{i}$ is found by Eq. (10) below:

$g_{i}(T)=h_{f^{0}}+\int_{T_{0}}^{T} C_{P} \mathrm{~d} T-T\left[s^{0}+\int_{T_{0}}^{T} \frac{C_{P}}{T} \mathrm{~d} T\right]$

where $C_{p}$ is specific heat value and is calculated by an experimental equation (Eq. 11), as follows:

$C_{P}=C_{0}+C_{1} \theta+C_{2} \theta^{2}+C_{3} \theta^{3}$

$C_{0}, C_{1}, C_{2}, C_{3}$ constants can be found in Table 2. Also $\theta$ equals to $\frac{T}{1000}$ where $T$ is in terms of Kelvin. 
Table 2 Coefficients for calculating specific heat value

\begin{tabular}{lcccc}
\hline Species & $\mathrm{C}_{0}$ & $\mathrm{C}_{1}$ & $\mathrm{C}_{1}$ & $\mathrm{C}_{2}$ \\
\hline $\mathrm{CO}_{2}$ & 0.45 & 1.67 & -1.27 & 0.39 \\
$\mathrm{H}_{2}$ & 13.46 & 4.6 & -6.85 & 3.79 \\
$\mathrm{CO}$ & 1.1 & -0.46 & 1 & -0.454 \\
$\mathrm{CH}_{4}$ & 1.2 & 3.25 & 0.75 & -0.71 \\
$\mathrm{O}_{2}$ & 0.88 & -0.0001 & 0.54 & -0.33 \\
\hline
\end{tabular}

\section{Membrane}

The membrane is needed for separation of hydrogen from the gas mixture. Membranes are a promising technology for separating gaseous components and have many advantages over acid gas removal units. When the objective is to obtain high-purity hydrogen, the dense metal membrane is used. These membranes are commonly made from palladium. One-layer porous ceramic or metal is also used in membrane's structure because of palladium's expense. Performance temperature of these membranes is almost between 300 and $600{ }^{\circ} \mathrm{C}$. Molecular hydrogen is adsorbed first onto the metal surface and dissociated to become atomic hydrogen. Then, the atomic $\mathrm{H}$ diffuses through the bulk metal layer in a direction which depends on the pressure gradient, and finally, hydrogen atoms recombine with each other and are desorbed in the form of $\mathrm{H}_{2}$ from the metal surface on the low-pressure side of the membrane as shown in Fig. 2 (Adhikari and Fernando 2006).

Activation energy for hydrogen permeation $\left(E_{\phi}\right)$ can be written in the form of Eq. (12) as follows (Al-Mufachi et al. 2015):

$E_{\phi}=E_{D}+E_{S}$

where $E_{D}$ and $E_{S}$ are the activation energy of diffusion and enthalpy of solution of hydrogen. At the temperatures above $150{ }^{\circ} \mathrm{C}$, reactions of combination and decomposition are in equilibrium form. The flow rate of hydrogen passed the membrane is calculated through first law of Fick, mentioned in Eq. (13) as follows (Al-Mufachi et al. 2015):

$J_{\mathrm{H}_{2}}=\frac{D_{\mathrm{H}} S_{\mathrm{H}}}{t}\left(P_{\text {per }}^{n}-P_{\text {ret }}^{n}\right)$

where $J_{\mathrm{H}_{2}}$ is flow flux, $D_{\mathrm{H}} S_{\mathrm{H}}$ is hydrogen's diffusion in membrane, $t$ is membrane's thickness, $n$ is partial pressure exponent which is usually between 0.5 and 2 , and $P_{\text {per }}$. and $P_{\text {ret }}$ are the outlet pressures of pure hydrogen (permit pressure) and the retentive pressure, respectively. For this membrane, $n=0.5$ is used. Diffusion of hydrogen in membrane can be obtained from Arrhenius relations which are mentioned by Eqs. $(14,15)$ as follows (Al-Mufachi et al. 2015):

$D_{\mathrm{H}}(T)=D_{0} \exp \left(-\frac{E_{D}}{R \cdot T}\right)$

$S_{\mathrm{H}}(T)=S_{0} \exp \left(-\frac{E_{S}}{R \cdot T}\right)$

$R$ is the global gas constant, and $T$ is reaction's temperature. $S_{0}$ and $D_{0}$ are solubility and diffusivity in infinite temperature. So, Eqs. (16-18) can be derived as below:

$Q_{0}=S_{0} D_{0}$

$Q=Q_{0} \exp \left(-\frac{E_{\phi}}{R \cdot T}\right)$

$J_{\mathrm{H}_{2}}=\frac{Q}{t}\left(P_{\mathrm{per}}^{n}-P_{\mathrm{ret}}^{n}\right)$

\section{Results and discussion}

\section{Effect of temperature}

The pressure of 300 bars and the bagasse concentration of $20 \mathrm{wt} \%$ were considered to investigate the effect of

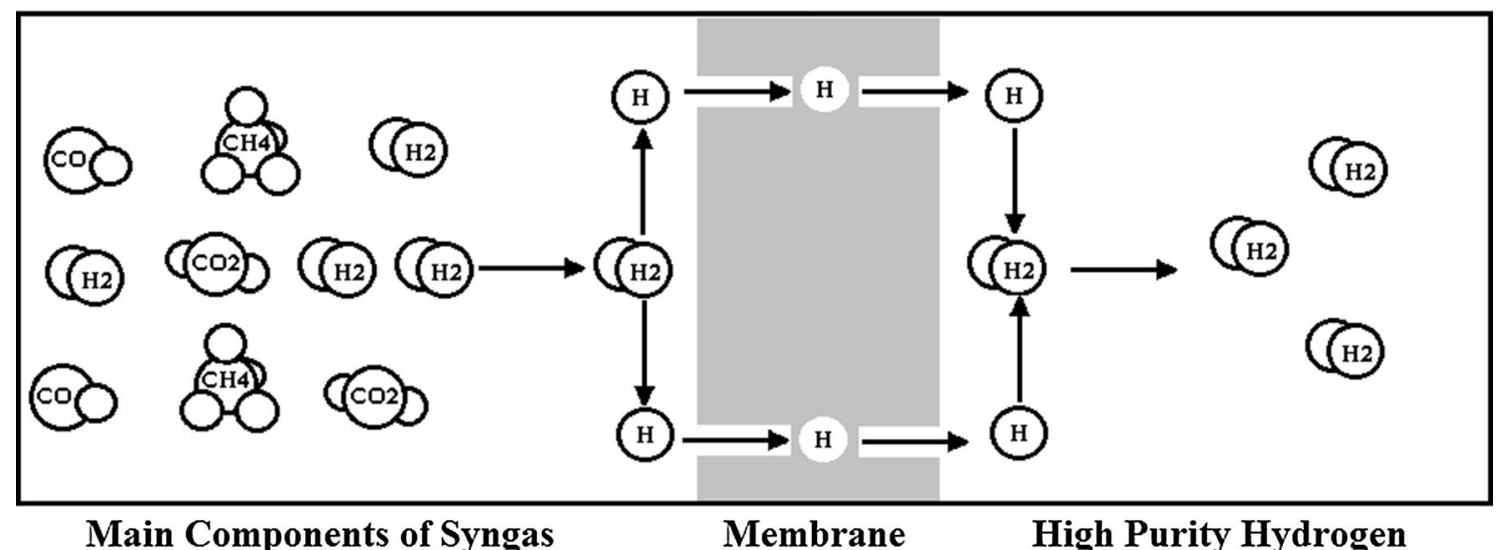

Fig. 2 Schematic for the mechanism of hydrogen-selective membrane 


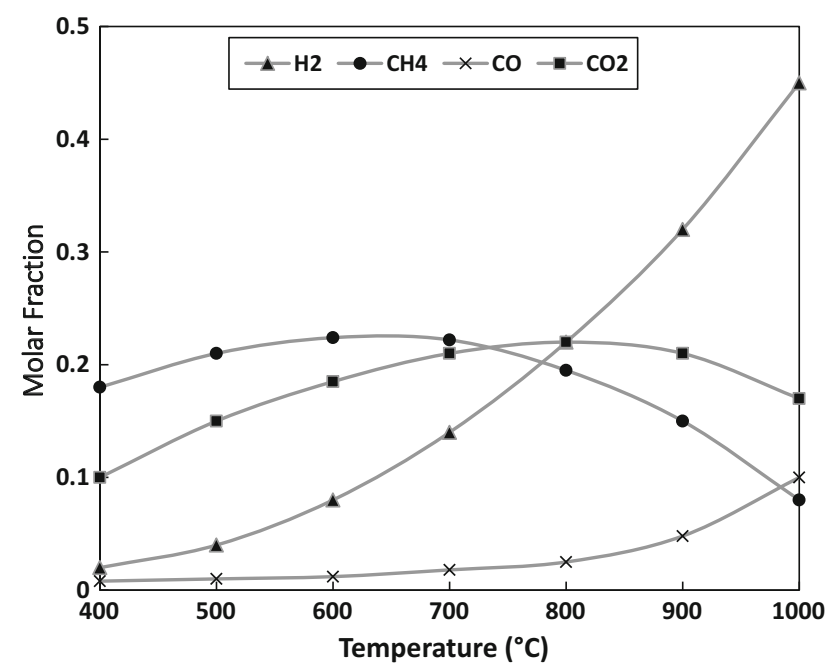

Fig. 3 Variation of the molar fraction of main gaseous components with temperature

temperature on main gaseous yields. Experimental studies have shown that increment of temperature follows with a significant effect on SCW gasification and promote the total gas and hydrogen yields (Sheikhdavoodi et al. 2014; Azadi et al. 2009). Figure 3 demonstrates the variation of main gaseous yields with temperatures from 400 to $1000{ }^{\circ} \mathrm{C}$. It is indicated that $\mathrm{H}_{2}$ yield increased drastically within this range of temperature with the promotion of endothermic steam reforming reaction (Eq. 19), while $\mathrm{CO}$ and $\mathrm{CH}_{4}$ remained approximately constant and $\mathrm{CO}_{2}$ increased slightly until the temperature of $800{ }^{\circ} \mathrm{C}$ and then, $\mathrm{CH}_{4}$ and $\mathrm{CO}_{2}$ started to decrease while $\mathrm{CO}$ increased. Moreover, the molar fraction of hydrogen increased from $2 \%$ in $400{ }^{\circ} \mathrm{C}$ to $48 \%$ in $1000{ }^{\circ} \mathrm{C}$. The reduction of methane can be due to the exothermic methanation, mentioned as Eq. (20), which do not promote with the increment of temperature.

$$
\begin{array}{r}
\mathrm{CH}_{x} \mathrm{O}_{y}+(1-y) \mathrm{H}_{2} \mathrm{O} \rightarrow \mathrm{CO}+\left(1-y+\frac{x}{2}\right) \mathrm{H}_{2} \\
\Delta H=+310\left(\frac{\mathrm{KJ}}{\mathrm{mol}}\right) \\
\mathrm{CO}+3 \mathrm{H}_{2} \rightarrow \mathrm{CH}_{4}+\mathrm{H}_{2} \mathrm{O} \quad \Delta H=-206\left(\frac{\mathrm{KJ}}{\mathrm{mol}}\right)
\end{array}
$$

\section{Effect of feed concentration}

The effect of variation of the sugarcane bagasse concentration of the mixture on gaseous components yields is studied. Pressure and temperature are considered to be 300 bars and $800{ }^{\circ} \mathrm{C}$, respectively. As shown in Fig. 4, the wt $\%$ of bagasse varies from 0 to 100 percent. $\mathrm{H}_{2}$ and $\mathrm{CO}_{2}$ are the main products of the syngas from 0 to $10 \mathrm{wt} \%$. Then, $\mathrm{CH}_{4}$

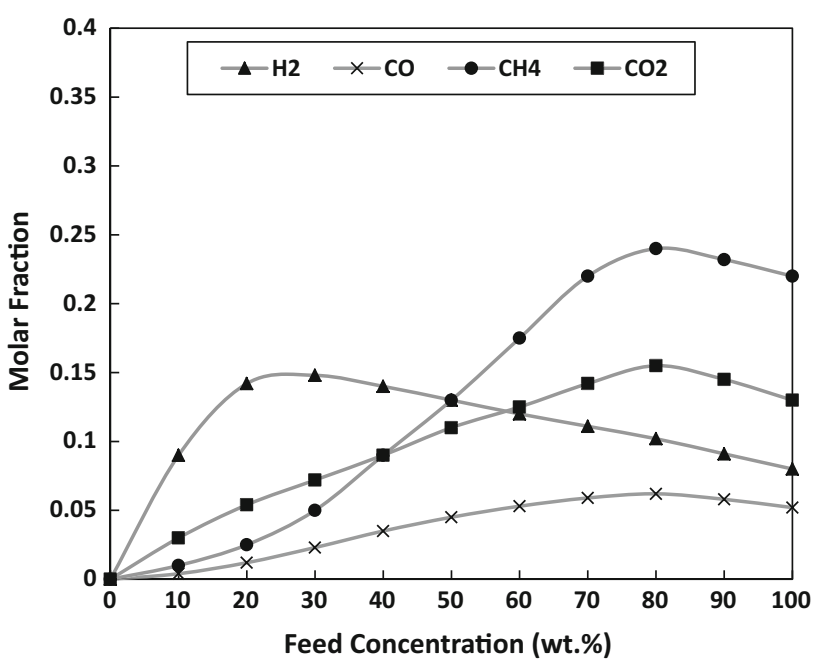

Fig. 4 Variation of the molar fraction of main gaseous components with feed concentration

and $\mathrm{CO}$ are generated gradually. Maximum $\mathrm{H}_{2}$ yield appeared at the concentration of near $30 \mathrm{wt} \%$, and then $\mathrm{H}_{2}$ decreases. Moreover, the yields of $\mathrm{CO}, \mathrm{CO}_{2}$, and $\mathrm{CH}_{4}$ increase until the concentration of $80 \mathrm{wt} \%$ and then decrease. This may be because of the methanation reaction that consumes $\mathrm{H}_{2}$ and produces $\mathrm{H}_{2} \mathrm{O}$. As seen in Fig. 4, the production of $\mathrm{CH}_{4}$ is promoted when $\mathrm{H}_{2}$ begins to decrease.

\section{Energy analysis}

As shown in Fig. 1, Pressure and temperature for the SCW gasification in the process are assumed to be 300 bars and $700{ }^{\circ} \mathrm{C}$. Mass flow rates for water and sugarcane bagasse are 800 and $200 \mathrm{~kg} / \mathrm{h}$, respectively.

The flow conditions for each part of the cycle has mentioned in Table 3.

If the diagram of Fig. 1 is considered as a control volume, five energy streams are obviously observed except the energy losses. Two of them are regarding heat transfer, and the others are regarded as electrical power. These five streams are described as follows:

1. Q-REACT: This stream is representing the amount of the heat consumed or generated by reactor which is determined via the operating temperature of the reactor and the concentration of the mixture. When the value is negative, which means that the reactions require an external energy to reach the equilibrium condition, the predicted $\mathrm{CH}_{4}$ stream can be activated and burned for heating supply. 
Table 3 Operating conditions for each part of the cycle

\begin{tabular}{|c|c|c|c|}
\hline Stream & Mass flow & Temperature $\left({ }^{\circ} \mathrm{C}\right)$ & Pressure (bar) \\
\hline $\mathrm{H}_{2} \mathrm{O}$ & 800 & 25 & 1 \\
\hline BIOMASS & 200 & 25 & 1 \\
\hline MIXED & 10,000 & 25 & 1 \\
\hline PUMPED & 1000 & 28.3 & 200 \\
\hline PREHEAT1 & 1000 & 297 & 300 \\
\hline PREHEAT2 & 1000 & 753 & 300 \\
\hline REACTOR & 1000 & 700 & 300 \\
\hline SYNGAS & 1000 & 700 & 300 \\
\hline SYNGAS2 & 1000 & 350 & 300 \\
\hline WATER & 749 & 350 & 300 \\
\hline GAS-1 & 251 & 60 & 300 \\
\hline GAS-2 & 251 & 490 & 300 \\
\hline Gas-3 & 251 & 310 & 60 \\
\hline GAS-4 & 241 & 310 & 60 \\
\hline $\mathrm{H}_{2}$ STREAM & 8.56 & 310 & 3 \\
\hline GAS-5 & 242 & 195 & 1 \\
\hline $\mathrm{CH} 4$ & - & - & - \\
\hline GAS-6 & 242 & 195 & 1 \\
\hline AIR & 1063 & 25 & 1 \\
\hline AIR-2 & 1063 & 255 & 1 \\
\hline FLUE & 1305 & 1733 & 1 \\
\hline FLUE2 & 1305 & 505 & 1 \\
\hline FLUE3 & 1305 & 280 & 1 \\
\hline
\end{tabular}

2. Q-SEPAR: This energy stream is due to the energy loss because of extraction of water at high temperature and its condensation. Its value is always positive.

3. W-PUMP: this stream is representing the energy consumed by the pump for pressurizing the mixture up to operating reactor's pressure.

4. W-TRBEX-1: It is representing the electrical power generated via the stream which makes work by expanding the gas in the first turbine

5. W-TRBEX-2: It represents the electrical power generated via the stream which makes work by expanding the gas in the second turbine

However, the maximum reachable work can be calculated using the first and the second laws of thermodynamics, which are mentioned in Eqs. $(21,22)$, as follows:

$\sum_{i} \dot{E}_{\text {in }}=\sum_{o} \dot{E}_{\text {out }}$

$\dot{W}_{\text {rev }}=\dot{m}\left[h_{\text {out }}-h_{\text {in }}\right]$.
The first turbine drops the pressure from 300 bars to 60 bars in order to prepare the gas for the separation of highpurity hydrogen. After that, the second turbine drops the separated syngas's pressure from 60 to 30 bars. The amount of hydrogen and power produced via this process has been brought in Table 4. It is for the mixture that includes $200 \mathrm{~kg}$ bagasse and $800 \mathrm{~kg}$ water.

\section{Cycle's efficiency}

Efficiencies for power generation are investigated in this part. Produced syngas has $1000 \mathrm{~kg} / \mathrm{h}$ flow rate. The lower heating value of the fuel and the produced gas are 17.33 and $18.04 \mathrm{MJ} / \mathrm{kg}$, respectively.

Efficiency for power generation in turbines is calculated via Eq. (23) as follows:

$\eta_{p}=\frac{\dot{W}_{\text {net }}}{\dot{W}_{p}+\dot{Q}_{\mathrm{CH}_{4}}} \times 100=\frac{54}{4.18+117} \times 100=44 \%$

Pure hydrogen produced via the process is storage with the flow rate of $8.55 \mathrm{~kg} / \mathrm{h}$, the temperature of $310^{\circ} \mathrm{C}$ and the pressure of 60 bars. The net efficiency for power generation is calculated via the Eq. (24).

$\eta_{\text {net }}=\frac{\dot{W}_{\text {net }}}{\dot{m}_{\text {fuel }} \mathrm{LHV}_{\text {fuel }}} \times 100=6.46 \%$

\section{Comparison with experimental results}

The results of this study are compared with some recent reports in the literature. Even though the current study simulates the gasification process in an industrial scale, the trend of variations of affecting parameters can be investigated. Safari et al. (2016) studied the SCW gasification of some agricultural waste in a batch reactor. Hydrogen was directly correlated with temperature and sharply increase when an increase in temperature which can be obviously seen in Fig. 3 of this study. Also, in another report, Barati et al. (2014) reported the effect of feed concentration on the yield of main gaseous products. Feed concentration was inversely associated with the hydrogen yield. As seen in Fig. 4 of this study, the molar fraction of hydrogen first increases and then decreases. This could be due to the small size of the reactor in the experimental study which limits the steam reforming in the relatively high concentrations.

Table 4 Hydrogen and electricity produced via the process for $200 \mathrm{~kg}$ of bagasse and $800 \mathrm{~kg}$ of water

\begin{tabular}{lllll}
\hline Feed & Temperature $\left({ }^{\circ} \mathrm{C}\right)$ & Pressure $($ bar $)$ & Hydrogen production $(\mathrm{kg})$ & Electric power $(\mathrm{kW})$ \\
\hline Bagasse & 700 & 300 & 8.55 & 56 \\
\hline
\end{tabular}




\section{Conclusion}

A significant amount of sugarcane bagasse which is estimated to be about 5 million tons is wasted or burned annually in Iran. Developing the conversion technologies for making fuels and chemicals from this renewable resource seems very necessary. This study represented a novel process for producing hydrogen and power via gasification of sugarcane bagasse in SCW media. The temperature was directly correlated with hydrogen production. While the feed concentration of 25-35 wt\% was a desirable range for maximum hydrogen production, $80 \mathrm{wt} \%$ concentration was the best concentration of sugarcane bagasse for maximum methane production. Energy analysis and cycle's efficiency were also investigated. This research was a new approach using promising biomass conversion technologies for utilization of bioenergy obtained from one of the main agricultural wastes in Iran and the world which has not been proposed before.

Acknowledgments The Authors gratefully thank the council for the development of renewable energy technologies of Iran's vice-presidency for science and technology, for their support of this research.

\section{References}

Adhikari S, Fernando S (2006) Hydrogen membrane separation techniques. Ind Eng Chem Res 45:875-881

Al-Mufachi NA, Rees NV, Steinberger-Wilkens R (2015) Hydrogen selective membranes: a review of palladium-based dense metal membranes. Renew Sust Energy Rev 47:540-551

Anwar Z, Gulfraz M, Irshad M (2014) Agro-industrial lignocellulosic biomass a key to unlock the future bio-energy: a brief review. J Radiation Res Appl Sci 7:163-167

Azadi P, Khoadadadi AA, Mortazavi Y, Farnood R (2009) Hydrothermal gasification of glucose using Raney nickel and homogeneous organometallic catalysts. Fuel Process Technol 90:145-151

Barati M, Babatabar M, Tavasoli A, Dalai AK, Das U (2014) Hydrogen production via supercritical water gasification of bagasse using unpromoted and zinc promoted $\mathrm{Ru} / \gamma-\mathrm{Al}_{2} \mathrm{O}_{3}$ nanocatalysts. Fuel Process Technol 123:140-148

Basu P, Mettanant V (2009) Biomass gasification in supercritical water-a review. Int J Chem React Eng 7:1-61

Casella F, Colonna P (2012) Dynamic modeling of IGCC power plants. Appl Therm Eng 35:91-111

Castello D, Fiori L (2011) Supercritical water gasification of biomass: thermodynamic constraints. Bioresour Technol 102:7574-7582

Castello D, Fiori L (2015) Supercritical water gasification of biomass: a stoichiometric thermodynamic model. Int J Hydrogen Energy 40:6771-6781

Cohce MK, Dincer I, Rosen MA (2010) Thermodynamic analysis of hydrogen production from biomass gasification. Int J Hydrogen Energy 35:4970-4980

Cohce MK, Dincer I, Rosen MA (2011) Energy and exergy analyses of a biomass-based hydrogen production system. Bioresour Technol 103:8466-8474
Desnoo B, Huang X (2013) Gasification of bio-waste and biomass products through exposure to HD and LD supercritical water. J Energy Power Eng 7:1922-1933

Dincer I (2012) Green methods for hydrogen production. Int J Hydrogen Energy 37:1954-1971

Furusawa T, Sato T, Sugito H, Miura Y, Ishiyama Y, Sato M, Itoh N, Suzuki N (2007) Hydrogen production from the gasification of lignin with nickel catalysts in supercritical water. Int J Hydrogen Energy 32:699-704

Kluiters SCA (2004) Status review on membrane systems for hydrogen separation. Intermediate report EU project, Migreyd NNE5

Kruse A, Dinjus E (2007) Hot compressed water as reaction medium and reactant. Properties and synthesis reactions. J Supercrit Fluid 39:362-380

Matsumura Y, Ishibe H (2009) Selective steam reforming of methanol over silica-supported copper catalyst prepared by sol-gel method. Appl Catal B Environ 86:114-120

Midilli A, Dincer I, Ay M (2006) Green energy strategies for sustainable development. Energy Policy 34:3623-3633

Nanda S, Mohammed J, Reddy SN, Kozinski JA, Dalai AK (2013) Pathways of lignocellulosic biomass conversion to renewable fuels. Biomass Convers Bioref 4:157-191

Ni M, Leung DYC, Leung MKH, Sumathy K (2006) An overview of hydrogen production from biomass. Fuel Process Technol $87: 461-482$

Norouzi O, Safari F, Jafarian S, Tavasoli A, Karimi A (2016) Hydrothermal gasification performance of Enteromorpha intestinalis as an algal biomass for hydrogen-rich gas production using $\mathrm{Ru}$ promoted $\mathrm{Fe}-\mathrm{Ni} / \mathrm{c}-\mathrm{Al}_{2} \mathrm{O}_{3}$ nanocatalysts. Energy Convers Manag. doi:10.1016/j.enconman.2016.04.083

Parthasarathy P, Narayanan KS (2014) Hydrogen production from steam gasification of biomass: influence of process parameters on hydrogen yield-a review. Renew Energy 66:570-579

Safari F, Tavasoli A, Ataei A, Choi JK (2015) Hydrogen and syngas production from gasification of lignocellulosic biomass in supercritical water media. Int $\mathrm{J}$ Recycl Org Waste Agric $4: 121-125$

Safari F, Salimi M, Tavasoli A, Ataei A (2016) Non-catalytic conversion of wheat straw, walnut shell and almond shell into hydrogen rich gas in supercritical water media. Chin $\mathrm{J}$ Chem Eng. doi:10.1016/j.cjche.2016.03.002

Sheikhdavoodi MJ, Almasi M, Ebrahimi-Nik M, Kruse A, Bahrami H (2014) Gasification of sugarcane bagasse in supercritical water; evaluation of alkali catalysts for maximum hydrogen production. J Energy. doi:10.1016/j.joei.2014.10.005

Shoja M, Babatabar MA, Tavasoli A, Ataei A (2013) Production of hydrogen and syngas via pyrolysis of bagasse in a dual bed reactor. J Energy Chem 22:639-644

Susanti RF, Dianningrum LW, Yum T, Kim Y, Gwon B, Kim J (2012) High-yield hydrogen production from glucose by supercritical water gasification without added catalyst. Int J Hydrogen Energy 37:11690-11697

Tavasoli A, Ahangari MG, Sony C, Dalai AK (2009) Production of hydrogen and syngas via gasification of the corn and wheat dry distiller grains (DDGS) in a fixed-bed micro reactor. Fuel Process Technol 90:472-482

Whitag JAM, Smeets JR, Bramer EA, Brem G (2012) System model for gasification of biomass model compounds in supercritical water-a thermodynamic analysis. J Supercrit Fluid 61:157-166

Yoon SY, Han SH, Shin SJ (2011) The effect of hemicelluloses and lignin on acid hydrolysis of cellulose. Energy 77:19-24 